\title{
A Study on the Dynamic Relationship between Cultural Industry and Economic Growth*
}

\author{
Yugang He
}

Received : July 7, 2018 Revised: July 26, 2018 Accepted: October 10, 2018

\begin{abstract}
The cultural industry is treated as the sunrise industry in modern society. It has taken an increasing role in promoting the economic growth. Due to this, this paper attempts to explore the dynamic relationship between cultural industry and the economic growth. On the grounds of Cobb-Douglas production function, the cultural industry is regarded as a determinant such as the labor input and the capital input to impact the economic growth. Meanwhile, the quarterly datum form 2000-Q1 to 2017-Q4 are employed to perform an empirical analysis via the vector error correction model. The GDP is treated as an independent variable. The input of capital, the input of labor and the total input of cultural industry are treated as dependent variables. Furthermore, a menu of statistical approaches such as the co-integration test and the impulse response function will be used to testify the dynamic relationship between cultural industry and economic growth. Via the Johansen co-integration test, the results report that the cultural industry has a obviously positive effect on economic growth. Through the vector error correction estimation, the results also report that the cultural industry also has a significantly positive effect on economic growth, but less than that of the Johansen co-integration test. This paper provides a view that the cultural industry is a kind of a determinant to promote the economic growth. Therefore, the China's government should pay much attention to the cultural industry construction.
\end{abstract}

Keywords: Cultural Industry, Economic Growth, Cobb-Douglas Production Function, Vector Error Correction Model.

JEL Classification Code: B55, C02, C51.

\section{Introduction}

The cultural industry is a kind of product or service which is based on the culture of a civilization, nation, society, group or place. Often, it is treated as a sunrise industry in modern society. As the cultural industry construction expansion, it has made a significant contribution to the economic growth. Therefore, a menu of countries have attached great importance to the cultural industry.

* The paper was presented initially at 2018 International Conference on Business and Economics (ICBE2018) and the 14th International Conference of KODISA that was held in Seoul, South Korea, June 25-27, 2018. The paper has been recognized as one of Best Paper Awards at ICBE2018 conference. This paper is a substantially revised and expanded version of the paper presented at ICBE2018 conference. I have taken into account all the comments of Editors, Session Chairs and Reviewers in the revised manuscript. I greatly appreciate Editors, Session Chairs and Reviewers for their valuable comments, interest in and support of this research.

1 First Author and Corresponding Author. Ph.D. Candidate, Department of International Trade, Chonbuk National University, South Korea. E-mail: 1293647581@jbnu.ac.kr
The cultural industry is centered on the creation of cultural content. It is a kind of economic form that provides cultural products and cultural services on a large scale through market-oriented and industrialized organizations. It is characterized by the combination of culture and economy, with the aim of meeting people's cultural needs and emphasizing the core of promoting social benefits by using economic benefits. The Cultural industry has become an important means to promote the optimization and adjustment of economic structure. At the same time, it has provided economic and cultural foundation for broadening the channels of employment and actively participating in international cultural competition. At present, compared with developed countries, the China's cultural industry has a potential demand for mass culture. In contrast, it has a great potential for development. China has a vast domestic demand market, which presents a strong guarantee to the development of the cultural industry. Meanwhile, the classical Chinese traditional culture has become more and more influential in the world, and the communication between China and world has been expanding day by day. For a long time, the situation of parallel disjunction between 
culture and economy has gradually changed, and the concept and pattern of mutual promotion of common growth between culture and economy are gradually taking shape.

The aim of this paper is to exploit the dynamic relationship between cultural industry and economic growth. On the grounds of Cobb-Douglas production function, the cultural industry is regarded as a determinant such as the labor input and the capital input to impact the economic growth. Meanwhile, the quarterly datum form 2000-Q1 to 2017-Q4 are employed to perform an empirical analysis via the vector error correction model. The GDP is treated as an independent variable. The input of capital, the input of labor and the total input of cultural industry are treated as dependent variables. Furthermore, a menu of statistical approaches such as the Augmented Dicky-Fuller test, the co-integration test, the Granger causality test, the vector error correction estimation, the impulse response function and the variance decomposition will be used to testify the dynamic relationship between cultural industry and economic growth. The findings of this paper exhibit that both in the long term and in the short term, the cultural industry has a positive effect on economic growth. However, the performance of cultural industry to drive the economic growth is more significant than that of long-run performance. Furthermore, this empirical evidence provides a suggestion that the China's government should spare no effort to expanse the cultural industry construction.

The rest of this study will be constructed as follows. Section two provides the literature review which is summarized from previous researches so as to make a distinction between this paper and others. Section three presents the theoretical framework which is always regarded as a foundation for this paper. Section four reports the empirical analysis which presents the theoretical evidences for this study. Section five exhibits the conclusion which is treated as a summary of this study.

\section{Literature Review}

The cultural industry is not merely the concentrated reflection that the culture and economy lend each other, but also it is a new growth engine. In the last twenty year, due to the huge improvement of people's material life, more focuses have been transferred to the importance of cultural industry, especially, the relation between cultural industry and economic growth. For this proposition, a large number of scholars have regarded the cultural industry as a driving factor of the economic growth and attempted to exploit the relationship between both of them.

Jiang (2009) employs the endogenous growth theory and the data of the 14 cities in Yangtze River Delta Area from
1992 to 2006 to conduct an empirical analysis on the relation between cultural industry and economic growth, as well as the operation mechanism of cultural industry's growth effect. His findings show that a significant positive relationship between cultural industry and economic growth exists in this area. Based the industrial structure optimization perspective. Cai (2010) finds that the cultural industry not only has a direct effect on economic growth, but also it has an indirect effect on economic growth. His findings show that the cultural industry has a strong diffusion effect, which is conducive to the optimization of industrial structure and has a significant power of pushing economy development. Due to the culture industry as a new sunrise industry, Li, Fang and Wang (2010) find that the contribution of cultural industry to economic growth is significant. Chen, $\mathrm{Li}$, and Gong (2010) set China's Hunan province as an example to analyse the impact of cultural industry on Hunan's GDP. They find that $1 \%$ increase in the added value of cultural industry will result in $0.62 \%$ increase in Hunan's GDP.

Li and Liu (2011) analyse the effect of cultural industry on economic growth by method of gray correlation degree. They use the same method to analyse the effect of cultural industry on three main industries and compare the different effects on GDP from the core layer, the outer layer, the relevant layer of cultural industry. Their findings show that the cultural industry has great impact on economic growth. The cultural industry have tremendous influence on the tertiary industry. The relevant layer of cultural industry has the greatest effect on economic growth. Chen and Wang (2011) treat China's Guangdong province as an example and attempt to analyze the impact of cultural industry and economic growth in terms of the input and output. They find that the influence coefficient of Guangdong's cultural industry is high. However, the sensitivity coefficient of Guangdong's cultural industry is low. The cultural industry plays an important role in Guangdong's economic growth, but it has not become a key sector of Guangdong's economic growth. Meanwhile, Zheng (2012) also sets Zhejiang province as study object. He finds that the cultural industry of Zhejiang province has a good correlation and ripple effect, which can drive the development of related industries. The development of cultural industry in Zhejiang province heavily depends on the cultural manufacturing industry. However, its products' added value is not so significant. Therefore, it is quite important to adjust the structure from cultural manufacturing to high-value-added cultural and creative industries. He also finds that the promoted-effect of cultural industry on economic growth is much greater than that of economic growth on cultural industry.

Panagiotis and Pantelis (2013) divide the cultural background variables into two main groups. They are the 
efficiency orientation variable and the social orientation variable. They propose a hypothesis that economic growth is significantly impacted in the well known growth framework efficiency pilot variables, while the social orientation influences are not predicted in principle. Their findings confirm that the cultural background positively affects annual growth rates. However, the social orientation plays the main positive role. Furthermore, performing a sensitivity analysis on the cultural background, their conclusions confirm that the cultural background has a strong interpretive role in annual growth rates. The deterioration of the social orientation cultural background negatively affects annual GDP growth. Ager and Brückner (2013) find that increases in cultural fractionalization significantly increase output, while increases in cultural polarization significantly decrease output.

International experts agree that the cultural action is a positive element in social and economic integration, a real way to promote territorial cohesion and a driving force for local development. Bălan and Vasile (2015) have a try to describe the influence of culture on the economy. They regard the culture as an economic asset such as a type of capital culture. They analyse the impact of romanian cultural factors and the creation sector on economic development at the national level and in developing regions. General speaking, they analyze the direct effect of culture on economic development (the creative and cultural sector, the contribution to the GDP of Romania, the growth rate, the number of jobs) and the effect of culture on economic development (the information and technology, the mutual dependence on the investment and the tourism industry). Rushton (2015) treats the art policy as a cultural factor that affects economic growth. He finds that the public investments in the arts can spur local economic development. Vasile and Begalli (2015) analyze the differences between the cultural patterns and the economic structure, and the impact of them on changing the economic paradigm by looking for synchronized ways to ensure economic competitiveness and social inclusion.

Nagimova, Zainullina, and Bulatov (2015) figure that the cultural industry is a vital factor that promotes the economic growth. Efentaki and Dimitropoulos (2015) verify the Greek folk dance as intangible cultural activities to attract tourists, as an alternative form of tourism, and investigate the Greek folk dance of the potential impact of tourism economic development. Seo (2015) attempts to study a special proposition that the creative cultural localization ways and information technology market of the Europe Union to converge the creative industries.

Boccella and Salerno (2016) draw a clear picture of creative and cultural industries and of the creative economy, as driving factors of economic growth and local development. Dastane, Lee and Yong (2016) set Malaysia as an example to discus the corporate cultural asymmetry in terms the Korean expatriates adjustments and the job satisfaction. Kim and Jung (2016) also investigate study this proposition in terms of the korean multi-cultural families. Piuchan, Chan, and Kaale (2017) investigate the economic and socio-cultural impacts from the burgeoning mainland Chinese tourists on Hong Kong residents. Their results show that the socio-cultural aspects are reported negatively with regard to culture, shopping and dining, and transportation but conversely, it has a positive impact on education and infrastructure. The economic aspect shows that residents accept and appreciate the economic benefits bring by the inflow of mainland Chinese tourists. Ochoa and Ramírez (2018) create a theoretical model that offers empirical evidence to explain the possibilities of growth and consolidation of spatial agglomerations endogenously from the endogenous growth theory to explain the emergence and consolidation of the Architecture Cluster at the Toronto Central Metropolitan Area in Canada. They test the hypothesis that cultural industries improve the development of the regional and local economy. The premise is to model accurate evidence that explains the importance of culture in relation to the generation of value and economic development.

In summary, the previous studies listed above analyze the impact of a component of cultural industry on economic growth. In this paper, the cultural industry which is measured by the total input of it is regarded as a driving factor of the economic growth. Further more, this paper also attempt to exploit the short-run and the long-run dynamic relationship between cultural industry and economic growth.

In order to be seen more intuitively, all previous studies cited in this paper will be exhibited in $\langle$ Table 1$\rangle$.

Table 1: Summary of Previous Studies

\begin{tabular}{|c|c|c|}
\hline Author & Year & $\begin{array}{c}\text { Relationship between } \\
\text { Cultural Industry and } \\
\text { Economic Growth }\end{array}$ \\
\hline Jiang & 2009 & significant positive effect \\
\hline Cai & 2010 & direct and indirect effect \\
\hline Li, Fang and Wang & 2010 & significant effect \\
\hline Chen, Li \& Gong & 2010 & positive effect \\
\hline Li \& Liu & 2011 & greatest effect \\
\hline Chen \& Wang & 2011 & not very significant \\
\hline Zheng & 2012 & mutual effect \\
\hline Panagiotis \& Pantelis & 2013 & negative effect \\
\hline Ager \& Brückner & 2013 & significant effect \\
\hline Bălan \& Vasile & 2015 & direct and indirect effect \\
\hline Rushton & 2015 & positive effect \\
\hline Vasile \& Begalli & 2015 & positive effect \\
\hline Nagimova, Zainullina \& Bulatov & 2015 & positive effect \\
\hline Efentaki \& Dimitropoulos & 2015 & positive effect \\
\hline Boccella \& Salerno & 2016 & positive effect \\
\hline Piuchan, Chan \& Kaale & 2017 & negative effect \\
\hline Ochoa \& Ramírez & 2018 & positive effect \\
\hline \multicolumn{2}{|c}{}
\end{tabular}




\section{Theoretical Framework}

The Cobb-Douglas production function is originally created by the United States mathematician C.W. Cobb and the economist Paul H. Douglas to explore the relationship between inputs and outputs. It is an improvement of the general form of production function that introduces the technical factor. It is a kind of economic mathematical model that is used to predict the production of a country and region's industrial system or analyzed the production path. Often, this kind of economic mathematical model is called the Cobb-Douglas production function. It is the most widely used form of production function in economics, and it plays an important role in the mathematical economics and econometrics' research and application. Based on historical data, they study the effects of United States' capital and labor on production from 1899 to 1922. They find the relationship between labor and capital in terms of output and input under the constant technical economy condition. However, it is difficult to reflect the impact of technological progress on the output of Cobb-Douglas production function because $A$ is treated as a constant. More importantly, in the Cobb-Douglas production function, if any kind of input is zero, the output will be zero. Therefore, for the production, each factor of production is necessary, and no one can be entirely replaced by another kind of element.

In economics and econometrics, actually, the CobbDouglas production function is treated as a special form of the production function, which is widely employed to denoted the technological relation between inputs and outputs.

The general form of the function included a single output with two factors gives:

$$
Y=A(t) L^{\alpha} K^{\beta} \mu
$$

Where $\mathrm{A}(\mathrm{t})$ represents productivity, a variable that can be interpreted as the level of general knowledge about the "arts" of production available in an economy. $Y$ denotes the product. $L$ denotes the labor input. $K$ denotes the capital input. $\beta$ is the elasticity of the level of production with respect to capital; $\beta$ can also be thought of as the level of participation of capital in the productive process, whereas $\alpha$ will be the level of participation of labor. $\mu$ is the stochastic disturbance.

On the basis of equation (1), the determinants of output are the capital input, the labor input and the level of general knowledge about the "arts" of production available in an economy. Due to the combination of $\alpha$ and $\beta$, it can be expressed into three forms.
If $\alpha+\beta=1$, the Cobb-Douglas production function exhibits the constant return to scale.

If $\alpha+\beta>1$, the Cobb-Douglas production function exhibits the increasing by a factor of time.

If $\alpha+\beta<1$, the Cobb-Douglas production function responds to the deceasing return-to-scale case.

"Cultural industry," which was created by critical theorists, Theodor Adorno from the year of 1903 to 1969 and Max Horkheimer from the year of 1895 to 1973 , in the chapter of the "cultural industry" as a critical word. According to the international organizations such as the UNESCO and the WTO, the cultural industry (sometimes also known as "creative industry") combines the creation, the production and the distribution of goods \& services that are the cultural in nature and usually are protected by the intellectual property rights. More broadly, the cultural industry includes text, music, television, film manufacturing, publishing, crafts and designs. For some countries, construction, vision and performance arts, sports, advertising and cultural tourism may involve increasing value and creating value for individuals and society. They are based on knowledge, labor intensive, creating jobs and wealth. By fostering innovation and an innovative society, cultural diversity will be maintained and economic benefits enhanced. Owing to its definition, the cultural industry can be regarded as an input element to impact the economic growth such as the capital input and the labor input.

In this paper, the cultural industry which will be regarded as an input element to impact the economic growth, will be put into the Cobb-Douglas production function to construct the dynamic relationship between cultural industry and economic more clear.

The new Cobb-Douglas production function with the element of cultural industry gives:

$$
Y=A(t) L^{\alpha} K^{\beta} C I^{\gamma} \mu
$$

Where $\mathrm{Y}, \mathrm{A}(\mathrm{t}), \mathrm{L}, \mathrm{K}, \alpha$ and $\beta$ are the same as the equation (1) mentioned. CI represents the input element of cultural industry. $\gamma$ represents the output elasticity of cultural industry.

Conducting the logarithm on the both sides of equation (2) gives:

$\log Y=\log A(t)+\alpha \log L+\beta \log K+\gamma \log C I+\mu$

More generally, the equation (3) can be rewritten:

$\log Y_{t}=C+\alpha \log L_{t}+\beta \log K_{t}+\gamma \log C I_{t}+\mu_{t}$ 
Where $C$ denotes the constant. The equation (4) is called the new Cobb-Douglas production function with the element of cultural industry. According to the value of $\gamma$, the relationship between cultural industry and economic growth can be confirmed. If $\gamma>0$, there will be a positive relationship between cultural industry and economic growth. Conversely, If $\gamma<0$, there will be a negative relationship between cultural industry and economic growth. Meanwhile, if $\gamma=0$, there will be no relationship between cultural industry and economic growth.

\section{Empirical Analysis}

\subsection{Data Description}

In this paper, there are four variables (GDP, input of capital, input of labor and total input of cultural industry). The GDP is treated as an independent variable. The capital input, the labor input and the total output of cultural industry are treated as dependent variables. All of them are sourced from the National Bureau of Statistics of the People's Republic of China and the China's year book. The quarterly datum from 2000-Q1 to 2017-Q4 are employed. For purpose of leaving the outliers out and zooming the heteroscedasticity out, all variables are taken logarithm. In order to be seen more intuitive, all variables will be shown in $<$ Table 2>.

Table 2: Variable Description

\begin{tabular}{|c|c|c|c|}
\hline Variable & $\begin{array}{c}\text { Logarithmi } \\
\text { c Form }\end{array}$ & Definition & Source \\
\hline GDP & $\log G D P$ & Real GDP & NBSPRC \\
\hline capital input & $\log K$ & $\begin{array}{c}\text { Real total input of } \\
\text { capital }\end{array}$ & NBSPRC \\
\hline labor input & $\log L$ & Employment figure & NBSPRC \\
\hline Cultural industry & $\log C I$ & $\begin{array}{c}\text { Real total input of } \\
\text { cultural industry }\end{array}$ & $\begin{array}{c}\text { China's } \\
\text { year book }\end{array}$ \\
\hline
\end{tabular}

Note: National Bureau of Statistics of the People's Republic of China.

\subsection{Unit Root Test}

Before conducting regression analysis, all variables should be kept stationary so as to avoid the spurious regression. At present, there are a quantity of technical methods to testify the stationarity of a variable. In this study, the Augmented Dicky-Fuller test will be implied to verify the stationarity of all variables.

The model (1) gives:

$$
\Delta Y_{t}=\delta Y_{t-1}+\sum_{i=1}^{m} \beta_{i} \Delta Y_{t-1}+\varepsilon_{1 t}
$$

The model (2) gives:

$$
\Delta Y_{t}=\alpha+\delta Y_{t-1}+\sum_{i=1}^{m} \beta_{i} \Delta Y_{t-1}+\varepsilon_{2 t}
$$

The model (3) gives:

$$
\Delta Y_{t}=\alpha+\beta t+\delta Y_{t-1}+\sum_{i=1}^{m} \beta_{i} \Delta Y_{t-1}+\varepsilon_{3 t}
$$

Where $Y$ represents four variables. $\alpha$ represents the constant. $\Delta$ represents the difference operator. $\beta_{t}$ represents the trend term. $\varepsilon_{t}$ represents the white noise.

The null hypothesis that $H_{1}: \delta=0$ means that the unit root exists, which reports that the variable is non-stationary. The alternative hypothesis that $H_{1}: \delta \neq 0$ means that the unit root does not exist, which reports that the variable is stationary. Only one of the consequences from any model rejects the null hypothesis, the variable can be considered stationary. The results of Augmented Dicky-Fuller test show in $\langle$ Table 3$\rangle$.

Table 3: Unit Root Test

\begin{tabular}{|c|c|c|c|c|c|l|}
\hline Variable & t-Statistic & 1\% test critical value & 5\% test critical value & 10\% test critical value & Prob. & Result \\
\hline $\log G D P$ & -1.366 & -3.533 & -2.906 & -2.591 & 0.594 & Non-rejected \\
\hline $\log L$ & -2.570 & -3.527 & -2.904 & -2.589 & 0.104 & Non-rejected \\
\hline $\log K$ & -0.809 & -3.533 & -2.906 & -2.591 & 0.810 & Non-rejected \\
\hline $\log C I$ & -1.202 & -3.533 & -2.906 & -2.591 & 0.669 & Non-rejected \\
\hline$\Delta \log G D P$ & -10.896 & -3.529 & -2.904 & -2.590 & 0.000 & Rejected \\
\hline$\Delta \log L$ & -4.381 & -3.540 & -2.909 & -2.592 & 0.001 & Rejected \\
\hline$\Delta \log K$ & -3.020 & -3.533 & -2.906 & -2.591 & 0.038 & Rejected \\
\hline$\Delta \log C I$ & -16.697 & -3.529 & -2.904 & -2.590 & 0.000 & Rejected \\
\hline
\end{tabular}

Note: $\Delta$ denotes the first difference operator. 
$<$ Table 3> exhibits the results of unit root test. The null hypothesis that a variable has unit root is non-rejected at its level. Namely, all of them are non-stationary at their levels. However, after performing the first difference, the null hypotheses that the variables do not have unit root are rejected at $5 \%$ significant level. In other word, all of them are stationary at $5 \%$ significant level. In summary, all of them are the process of $\mathrm{I}(1)$. Therefore, a co-integration test needs to be conducted to confirm the long-run relationship among them.

\subsection{Co-integration Test}

At present, the most commonly used methods to conduct a co-integration are the Engle-Granger two-step-method and the Johansen co-integration test. Due to that the Johansen co-integration test can process more variables' co-integration relationship than that of the Engle-Granger two-step-method, the Johansen co-integration test will be employed in this paper to conduct a co-integration relationship among $\log \mathrm{GDP}, \log \mathrm{L}, \log \mathrm{K}$, and $\log \mathrm{CI}$. The results of Johansen co-integration test exhibit in <Table 4> and $<$ Table $5>$.

Table 4: Unrestricted Cointegration Rank Test (Trance)

\begin{tabular}{|c|c|c|c|c|}
\hline $\begin{array}{c}\text { Hypothesized } \\
\text { No. of CE(s) }\end{array}$ & Eigenvalue & $\begin{array}{c}\text { Trace } \\
\text { Statistic }\end{array}$ & $\begin{array}{c}\mathbf{0 . 0 5} \\
\text { Critical } \\
\text { Value }\end{array}$ & Prob.** $^{*}$ \\
\hline$r=0^{*}$ & 0.987 & 332.223 & 47.856 & 0.000 \\
\hline$r \leq 1^{*}$ & 0.201 & 30.724 & 29.797 & 0.039 \\
\hline$r \leq 2$ & 0.150 & 15.227 & 15.495 & 0.055 \\
\hline$r \leq 3^{*}$ & 0.056 & 3.992 & 3.841 & 0.046 \\
\hline
\end{tabular}

Note: 1) Trace test indicates 2 cointegrating eqn(s) at the 0.05 level.

2) *denotes rejection of the hypothesis at the 0.05 level.

3) **Mackinnon-Haug-Michelis (1999) p-values.

Table 5: Unrestricted Cointegration Rank Test (Maximum Eigenvalue)

\begin{tabular}{|c|c|c|c|c|}
\hline $\begin{array}{c}\text { Hypothesized } \\
\text { No. of CE(s) }\end{array}$ & Eigenvalue & $\begin{array}{c}\text { Max-Eigen } \\
\text { Statistic }\end{array}$ & $\begin{array}{c}\mathbf{0 . 0 5} \\
\text { Critical } \\
\text { Value }\end{array}$ & Prob.** $^{*}$ \\
\hline$r=0^{*}$ & 0.987 & 301.498 & 27.584 & 0.000 \\
\hline$r=1$ & 0.201 & 15.497 & 21.132 & 0.256 \\
\hline$r=2$ & 0.150 & 11.235 & 14.265 & 0.143 \\
\hline$r=3$ & 0.056 & 3.992 & 3.841 & 0.046 \\
\hline
\end{tabular}

Note: 1) Max-Eigenvalue test indicates 1 cointegrating eqn(s) at the 0.05 level.

2) *denotes rejection of the hypothesis at the 0.05 level.

$3)^{* *}$ Mackinnon-Haug-Michelis (1999) p-values.

The null hypothesis that the co-integration relationship among them does not exist is non-rejected when the value of trace and Max-Eigen statistic is less than $5 \%$ critical value. $<$ Table $3>$ and $<$ Table $4>$ report that the null hypothesis that the co-integration relationship among them does not exist is rejected because the value of trace and Max-Eigen statistic is greater than $5 \%$ critical value. In short, it can be confirmed that the co-integration relationship among them exists. And <Table 6> shows the coefficients of cointegrated equation.

Table 6: Coefficients of Co-integrating Equation

\begin{tabular}{|c|c|c|c|c|}
\hline Variable & $\operatorname{logGDP}$ & $\operatorname{logCI}$ & $\log \mathrm{L}$ & $\log \mathrm{K}$ \\
\hline $\begin{array}{c}\text { Normalized } \\
\text { co-integrating } \\
\text { coefficients }\end{array}$ & 1.000 & $\begin{array}{c}0.555 \\
(0.050)\end{array}$ & $\begin{array}{c}6.086 \\
(1.284)\end{array}$ & $\begin{array}{c}-0.413 \\
(0.051)\end{array}$ \\
\hline
\end{tabular}

Note: Standard error in parentheses.

The co-integrating equation gives:

$$
\log G D P_{t}=0.555 \log C I_{t}+6.086 \log L_{t}-0.413 \log K_{t}
$$

Equation (8) indicates the long-run relationship among $\log \mathrm{GDP}, \log \mathrm{L}, \log \mathrm{K}$ and $\log \mathrm{CI}$. It can be conclude that the $\log \mathrm{CI}$ and the $\log \mathrm{L}$ has a positive effect on $\log \mathrm{GDP}$. the $\log \mathrm{K}$ has a negative effect on $\operatorname{logGDP}$. More specifically, $1 \%$ increase in $\log \mathrm{CI}$ will result in $0.555 \%$ increase in $\log \mathrm{GDP} .1 \%$ increase in $\log \mathrm{L}$ will lead to $6.086 \%$ increase in $\log \mathrm{GDP} .1 \%$ increase in $\log \mathrm{K}$ will bring about $0.413 \%$ decrease in $\operatorname{logK}$. This result matches the real situation (focus on cultural industry construction, labor intensive and foreign investment expansion) of China.

\subsection{Granger Casualty Test}

The vector auto regression model aims to interpret that a change of a variable will be restricted by itself and other variables' past performance. However, a menu of variables exist the interacted relationship. Namely, the past value of a variable will be affected by the current value of another value or the past values of them will be affected by the current value of them. The Granger casualty test provides a method to test the casualty among them.

For two variables $X$ and $Y$, the model of the Granger casualty test gives:

$$
\begin{aligned}
& Y_{t}=\alpha+\sum_{i=1}^{m} \beta_{i} Y_{t-i}+\sum_{i=1}^{m} \alpha_{i} X_{t-i} \\
& X_{t}=\gamma+\sum_{i=1}^{m} \gamma_{i} Y_{t-i}+\sum_{i=1}^{m} \lambda_{i} X_{t-i}
\end{aligned}
$$

The Granger casualty test is performed via the restricted F-test. If the the statistic value of F-test is greater than the $5 \%$ critical value, the null hypothesis that the casualty relationship dose not exist will be rejected. The results of Granger casualty test show in $<$ Table $7>$. 
Table 7: Pariwise Granger Causality Tests

\begin{tabular}{|c|c|c|c|c|c|}
\hline lags & Null Hypothesis & Obs & F-Statistic & Prob. & Result \\
\hline \multirow{2}{*}{5} & $\log C I$ does not Granger Cause $\log G D P$ & \multirow{2}{*}{67} & 3.115 & 0.015 & Rejected \\
\hline & $\log G D P$ does not Granger Cause $\log C I$ & & 0.866 & 0.510 & Non-rejected \\
\hline 5 & $\log G D P$ does not Granger Cause $\log K$ & 67 & 4.571 & 0.001 & Rejected \\
\hline 5 & $\log L$ does not Granger Cause $\log G D P$ & 67 & 1.562 & 0.186 & Non-rejected \\
\hline
\end{tabular}

Table 8: Estimated Coefficients

\begin{tabular}{|c|c|c|c|c|c|c|c|c|c|c|c|}
\hline $\boldsymbol{\alpha}$ & $\boldsymbol{\beta}$ & $\boldsymbol{\gamma}$ & $\boldsymbol{\delta}$ & $\boldsymbol{\eta}$ & $\boldsymbol{\sigma}$ & $\boldsymbol{\theta}$ & $\boldsymbol{\eta}$ & $\boldsymbol{\lambda}$ & $\boldsymbol{\boldsymbol { \vartheta }}$ & $\boldsymbol{\rho}$ & $\boldsymbol{\phi}$ \\
\hline-0.412 & 4.587 & -5.983 & 0.217 & -3.080 & 0.224 & 5.090 & -3.080 & & \\
$(0.144)$ & $(2.239)$ & $(2.067)$ & $(0.020)$ & $(0.425)$ & $(0.021)$ & $(0.472)$ & $(0.425)$ & 1.412 & -0.989 & 0.312 & 1.424 \\
{$[0.006]$} & {$[0.045]$} & {$[0.042]$} & {$[0.000]$} & $(0.047)$ & $(0.000)$ & $(0.000$ & {$[0.000]$} & & \\
\hline
\end{tabular}

Note: ( ) represents the standard error; [ ] represents the p-value

$<$ Table 7> reports the results of Granger casualty test. There is an unidirectional causality relationship from $\log C \mathrm{I}$ to $\operatorname{logGDP}$. It means that the past value of $\log \mathrm{CI}$ can be used to predict the value of logGDP. However, the past value of $\operatorname{logGDP}$ can not be used to predict the current value of $\log \mathrm{CI}$; There is a bilateral causality relationship between $\log \mathrm{K}$ and $\log \mathrm{GDP}$. It means that the past value of $\operatorname{logK}$ and $\operatorname{logGDP}$ can be used to predict the current value of $\log \mathrm{K}$ and $\log \mathrm{GDP}$ respectively; There is no causality relationship between $\log \mathrm{L}$ and $\log \mathrm{GDP}$. It means that the past value of $\log \mathrm{L}$ and $\log \mathrm{GDP}$ can not be used to predict the current value of $\log \mathrm{L}$ and $\log \mathrm{GDP}$ respectively. This sector is also in keeping with the co-integration test.

\subsection{Vector Error Correction Model}

According to the results of the previous co-integration test, $\log \mathrm{GDP}, \log \mathrm{L}, \log \mathrm{K}$ and $\log \mathrm{CI}$ are the process of $\mathrm{I}(\mathrm{t})$. Furthermore, the co-integration relationship among them exists. Therefore, the auto-regressive distributed lag model $(1,1)$ gives:

$$
\begin{aligned}
& \log G D P_{t}=\alpha \log G D P_{t-1}+\beta \log C I_{t}+\gamma \log C I_{t-1} \\
& +\delta \log L_{t}+\sigma \log L_{t-1}+\eta \log K_{t}+\theta \log K_{t-1}+\varepsilon_{t}
\end{aligned}
$$

Rewriting equation (11) gives:

$$
\begin{aligned}
& \Delta \log G D P_{t}=\beta \Delta \log C I_{t}+\delta \Delta \log L_{t}+\eta \Delta \log K_{t} \\
& +\lambda\left(\log G D P_{t-1}-\vartheta \log C I_{t-1}-\rho \log L_{t-1}-\phi \log K_{t-1}\right)+\varepsilon_{t}
\end{aligned}
$$

Combining the equation (11) and the equation (12) gives:

$$
\begin{aligned}
& \lambda=1-\alpha \\
& \vartheta=\frac{\beta+\gamma}{\lambda} \\
& \rho=\frac{\delta+\sigma}{\lambda} \\
& \phi=\frac{\eta+\theta}{\lambda}
\end{aligned}
$$

Rewriting equation (12) gives:

$$
\begin{aligned}
& \Delta \log G D P_{t}=\beta \Delta \log C I_{t}+\delta \Delta \log L_{t} \\
& +\eta \Delta \log K_{t}+\lambda e c m_{t-1}+\varepsilon_{t}
\end{aligned}
$$

Where $\mathrm{ecm}_{t-1}$ is the error correction term.

The vector error correction model gives:

$$
\begin{aligned}
& \Delta \log G D P_{t}=4.587 \Delta \log C I_{t}+0.217 \Delta \log L_{t} \\
& -3.080 \Delta \log K_{t}+1.412 e c m_{-1}+\varepsilon_{t}
\end{aligned}
$$

Equation (18) is the short-relationship among logGDP, $\log \mathrm{L}, \log \mathrm{K}$ and $\log \mathrm{CI}$. It can be observed that $\Delta \log C I_{t}$ and $\log L \Delta \log L_{t}$ have a positive effect on $\Delta \log G D P_{t} . \Delta \log K_{t}$ has a negative effect on $\Delta \log G D P_{t}$. Concretely speaking, $1 \%$ increase in $\Delta \log C I_{t}$ will result in $4.587 \%$ increase in $\Delta \log G D P_{t} .1 \%$ increase in $\Delta \log L_{t}$ will give a rise to increase in $\Delta \log G D P_{t} .1 \%$ increase in $\Delta \log K_{t}$ will cause $3.080 \%$ decrease in $\Delta \log G D P_{t}$. Most importantly, when the system is 
deviate from the long-run equilibrium state in the short run, there will be a adjusting mechanism that can make the short-run deviation back to the long-run equilibrium state. The coefficient of $e^{c m_{t-1}}$ is 1.412 , which means that when the system is deviate from the long-run equilibrium state in the short run, the system will be back to the long-run equilibrium by $1.412 \%$ (positive direction).

\subsection{Impulse Response Function}

The impulse response function demonstrates that the shock of the sum of the disturbance term and a standard deviation to impact the current and future value of a variable via the the dynamic connection of variables in the vector error correction model. Namely, the impulse response function depicts that the system dynamically responds to a shock or new innovation of a variable's disturbance. Meanwhile, the lagged relationship between variables also can be acquired in the dynamic response. <Figure 1> shows the response of logGDP to cholesky standard innovations.

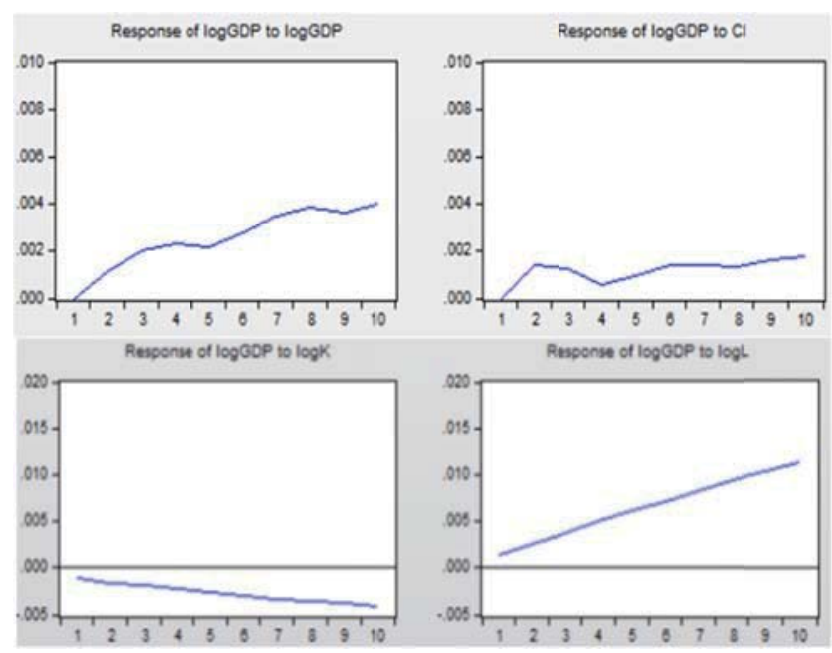

Figure 1: Response of logGDP to cholesky standard innovations.

The short-run dynamics among $\log G D P, \log \mathrm{L}, \log \mathrm{K}$ and $\log \mathrm{CI}$ can be examined by estimating a vector error correction model and interpreting it via the impulse response function. The impulse response function is reported for ten quarters in <Figure 1>. As for the response of logGDP to $\operatorname{logGDP}$, the $\operatorname{logGDP}$ increases slightly in response to one standard deviation shock in itself in the fourth quarter. And then, the effect of the shock will become negative. After that, the effect of the shock will become positive again until to eighth period. With a small decrease, the effect of the shock will keep increasing. Considering the response of logGDP to $\log \mathrm{CI}$, the $\operatorname{logGDP}$ will increase intensively in response to one standard deviation shock in $\log \mathrm{CI}$ in the second quarter. Then, the effect of the shock will decrease until to fourth period. After that, the effect of the shock will keep increasing again. Regarding the response of $\log \mathrm{CI}$ to $\log \mathrm{K}$, the $\log \mathrm{GDP}$ will increase immediately in response to one standard deviation shock in $\log \mathrm{K}$. And the effect of the shock has the trend to expanse. With respect to the response of logGDP to $\log$, the $\log G D P$ will fiercely increase in response to one standard deviation shock in $\log \mathrm{L}$. And the effect of the shock also has the trend to expanse, but greater than that $\log L$. The results of the impulse response function is in line with the results of Johansen co-integration test and the vector error correction estimation.

\subsection{Variance Decomposition}

The variance decomposition describes another dynamic change method of the system. The function of this method is to decompose the systematic forecasting average variance into the contribution of each variable's shock in the system. Therefore, the relative importance of each variable's shock to the system can be confirmed. Via comparing these shocks as time goes by, the time-lagged effect of variables can be estimated. Meanwhile, the magnitude of each variable's time-lagged effect also can be estimated. Namely, it is the ratio of the contribution of a variable's shock to the total contribution of them. The results of the variance decomposition of logGDP show in <Table 9>.

Table 9: Variance Decomposition of $\log \mathrm{GDP}$

\begin{tabular}{|c|c|c|c|c|c|}
\hline Period & S.E. & $\operatorname{logGDP}$ & $\log \mathrm{CI}$ & $\log \mathbf{L}$ & $\log \mathbf{K}$ \\
\hline 1 & 0.035 & 100.000 & 0.000 & 0.000 & 0.000 \\
\hline 2 & 0.043 & 81.200 & 2.386 & 0.086 & 16.328 \\
\hline 3 & 0.044 & 78.150 & 4.144 & 1.836 & 15.869 \\
\hline 4 & 0.057 & 77.029 & 4.798 & 1.903 & 16.270 \\
\hline 5 & 0.062 & 85.104 & 3.615 & 1.166 & 10.116 \\
\hline 6 & 0.062 & 76.025 & 4.602 & 1.048 & 18.325 \\
\hline 7 & 0.063 & 73.498 & 6.115 & 2.329 & 18.058 \\
\hline 8 & 0.064 & 72.430 & 6.611 & 2.507 & 18.452 \\
\hline 9 & 0.073 & 77.884 & 5.840 & 1.939 & 14.336 \\
\hline 10 & 0.077 & 72.003 & 6.244 & 2.114 & 19.916 \\
\hline
\end{tabular}

Regarding the variance decomposition, <Table 9> reports the variance decomposition for ten quarters forecast of $\operatorname{logGDP}$ in which $72.003 \%$ of the forecast variance is attributed to logGDP's shocks, while $6.244 \%$ to $\operatorname{logCI}$ 's shocks, $2.114 \%$ to $\log$ L's shocks and $19.916 \%$ to $\operatorname{logK}$ 's 
shocks. This results also is in step with the results of previous tests.

\section{Conclusion}

This paper attempts to exploit the the dynamic relationship between cultural industry and economic growth. On the grounds of Cobb-Douglas production function, the cultural industry is regarded as a determinant such as the labor input and the capita input to impact the economic growth. Meanwhile, the quarterly datum form 2000-Q1 to 2017-Q4 are employed to conduct an empirical analysis under the vector error correction model. The GDP is treated as an independent variable. The capital input, the labor input and the total output of cultural industry are treated as dependent variables. Furthermore, a menu of statistic approaches such as the Augmented Dicky-Fuller test, the co-integration test, the Granger causality test, the vector error correction estimation, the impulse response function and the variance decomposition will be used to testify the dynamic relationship between cultural industry and economic growth.

The results Johansen co-integration test reveal that the long-run relationship between cultural industry and economic growth exists. Concretely speaking, the cultural industry has a positive effect on economic growth. Meanwhile the labor input also has a significantly positive effect on economic growth. Conversely, the capital input has a negative effect on economic growth. The results of Granger causality test indicate that the cultural industry is a driving factor to the promote economic growth. However, the economic growth is a reason to promote the cultural industry development, which can not be confirmed. The results of vector error correction estimation show that there is a shortrun relationship between cultural industry and economic growth. Specifically, the cultural industry has a positive effect on economic growth, but less than that of Johansen co-integration test. When the impact of cultural industry to the economic growth is deviate from the long-run equilibrium, the coefficient of the error correction term is positive. Therefore, the system is deviate from the long-run equilibrium state in the short run, the system will be back to the long-run equilibrium in the positive direction. The results of the impulse response function and the variance decomposition exhibit that the cultural industry is also a major factor to drive the economic growth.

In summary, the cultural industry is treated as the sunrise industry in modern society. It has taken an increasing role in promoting economic growth. This paper also presents an empirical evidence to manifest that the cultural industry is a driving factor such as the labor input and the capital input to promote the economic growth. Therefore, the China's government should pay much attention to the cultural industry construction so as to keep high-speed economic growth.

\section{References}

Ager, P., \& Brückner, M. (2013). Cultural diversity and economic growth: Evidence from the US during the age of mass migration. European Economic Review, 64(1), 7697.

Bălan, M., \& Vasile, V. (2015). Cultural determinants of economic performance in Romania. Procedia-Social and Behavioral Sciences, 188(2), 290-296.

Boccella, N., \& Salerno, I. (2016). Creative economy, cultural industries and local development. Procedia-Social and Behavioral Sciences, 223(1), 291-296.

Cai, W. C. (2010). The impact of cultural industry on economic growth: Based on the perspective of industrial structure optimization. Xinhua Digest, (23), 48-50.

Chen, S. Q, Li, J.J., \& Gong, F. (2010). The Empirical Analysis of Influences from Cultural Industry Development on Regional Economic Growth. The Theory and Practice of Finance and Economics, 31(6), 98-101.

Dastane, O., Lee, W., \& Yong, W. (2016). Korean Expatriates Adjustments and Job Satisfaction in Malaysia: Analysis of Corporate Cultural Asymmetry.International. Journal of Industrial Distribution \& Business, 7(4), 33-45.

Efentaki, K., \& Dimitropoulos, V. (2015). Economic perspectives of intangible cultural activities. ProcediaSocial and Behavioral Sciences, 175(1), 415-422.

Huang, X. J., Chen, R. S., \& Wang, P. (2011). Cultural Industry Influences on Economic Growth Based on Inpoutput Analysis: A Case from Guangdong. Journal of Guangzhou University(Social Science Edition), 10(7), 4753.

Jiang, W. L. (2009). Cultural industry and regional economic growth: The evidence from 14 cities in Yangtze River delta area [J]. Journal of Zhongnan University of Economics and Law, 2, 84-88.

Kim, J. J., \& Jung, M. H. (2016). Investigation on the consciousness in business foundation motives for small business enterprisers in korean multi-cultural families. Journal of Distribution Science, 14(12), 53-59.

Li, H. L, Fang, Y., \& Wang, J. J. (2010). Research on Cultural Industry and Economic Growth. On Economic Problems, 12(2), 26-29.

Li, Z. F., \& Liu, W. Q. (2011). An Empirical Study on the Effect of Cultural Industry on Economic Growth in China. Forward Position or Economics, 11(5), 5-13. 
Nagimova, A. M., Zainullina, M. R., \& Bulatov, A. N. (2015). Socio-Economic Perspective on Cultural Consumption of the Population. Procedia Economics and Finance, 24(1), 470-478.

Ochoa, E. A., \& Ramírez, P. M. C. (2018). Cultural industries and spatial economic growth a model for the emergence of the creative cluster in the architecture of Toronto. City, Culture and Society, 25(1), 18-30.

Panagiotis Petrakis \& Pantelis Kostis. (2013). Economic growth and cultural change. The Journal of SocioEconomics, 47(2), 147-157.

Piuchan, M., Chan, C. W., \& Kaale, J. (2017). Economic and socio-cultural impacts of Mainland Chinese tourists on Hong Kong residents. Kasetsart Journal of Social Sciences. 14(1), 35-42.
Rushton, M. (2015). Cultural districts and economic development in American cities. Poetics, 49(1), 20-29.

Seo, D. (2015). Creative Cultural Localization Ways and IT Market of the EU to Converge the Creative Industries. Journal of Distribution Science, 13(1), 27-33.

Vasile, A. J., \& Begalli, D. (2015). Romania and the European economic and cultural model. Changing the paradigms. Procedia Economics and Finance, 22(1), 370379.

Zheng, S.H. (2012). An Empirical Study on the Role of Cultural Industry in Promoting Economic Growth: Based on the Analysis of Input-output of zhejiang Province in 2007. Productivity Research, 11(4), 194-195. 